ETAF ALKHLAIFAT ${ }^{1}$

DOI: $10.15290 / C R .2020 .30 .3 .01$

Western Sydney University

ORCID: 0000-0001-9831-6377

PING YANG ${ }^{2}$

Western Sydney University

ORCID: 0000-0002-3646-438X

MOHAMED MOUSTAKIM ${ }^{3}$

Western Sydney University

ORCID: 0000-0002-2847-1619

\title{
Code-switching between Arabic and English during Jordanian GP consultations
}

\begin{abstract}
This study draws conceptually on communication accommodation theory (CAT) to describe and analyze conversations between doctors and patients to identify the psycholinguistic and social motivations for code-switching (CS) between English and Arabic languages during medical consultations in Jordan. The researchers employ a thematic qualitative approach to interpret the phenomena under study. GP doctors $(n=9)$ and patients $(n=18)$ were observed and video-recorded in real medical settings and subsequently interviewed. This generated a comprehensive audio and videotaped corpus of data, which revealed that doctors and patients used code-switching during the medical consultation for two main reasons: 1) filling lexical gaps and 2) accommodating the other party. Jordanian bilingual doctors code-switched from English to Arabic and from Arabic to English to bridge lexical gaps, while both doctors and patients adapted their speech styles for the purpose of convergence. This study is significant as it investigates and examines the phenomenon of code-switching among Jordanian doctors and patients from psycholinguistic and social perspectives to gain a clearly defined sociolinguistic explanation of code-switching phenomena during their clinical interaction.
\end{abstract}

Keywords: bilingualism; code-switching; Communication Accommodation Theory; health care settings; thematic analysis.

1 Address for correspondence: School of Humanities and Communication Arts, Western Sydney University Locked Bag 1797, Penrith NSW 2751, Australia. E-mail: 18838594@student.westernsydney.edu.au

2 Address for correspondence: School of Humanities and Communication Arts, Western Sydney University Locked Bag 1797, Penrith NSW 2751, Australia. E-mail: p.yang@westernsydney.edu.au

3 Address for correspondence: School of Education, Western Sydney University Locked Bag 1797, Penrith NSW 2751, Australia. E-mail: m.moustakimawesternsydney.edu.au 


\section{Background}

A study of code-switching is intricately tied to the study of bilingualism. A bilingual speaker can shift effortlessly between L1 and L2 (Bullock \& Toribio 2009) under specific situations and conditions in response to linguistic, psychological, social, or pragmatic factors (Nilep 2006). According to Hamers et al. (2000: 6), bilinguality is "the psychological state of an individual who has access to more than one linguistic code as a means of social communication". Thus, in the case of the bilingual Jordanian doctors, when communicating the details of a diagnosis or treatment, they switch between English medical jargon and the Arabic language more frequently.

In Jordan, English has been the language of instruction in medical science since its introduction in the early $20^{\text {th }}$ century (Hamdan \& Hatab 2009). Accordingly, Arabicspeaking doctors are educated and trained exclusively in English, which makes all doctors in Jordan bilingual (Obeidat \& Khrais 2016). The patients, however, are mostly monolingual, as Arabic is the official language in Jordan (Al-Wer 2005). This situation can often affect the patients' comprehension due to their limited English language skills and their constrained health literacy.

Furthermore, doctors find communication with their patients challenging in the clinical setting when they use medical terms in English (Simmons 1998; Farahani et al. 2011; O'Connell et al. 2013; Galanti 2014; Fage-Butler \& Nisbeth Jensen 2016). They try to avoid using English and speak Arabic, particularly when interacting with patients with low levels of education and socioeconomic backgrounds. However, Jordanian patients speak diverse dialects in the urban and rural areas (Jarbou 2010; Al Masaeed 2013), and this may affect their communication with their doctors, and often results in misunderstanding and confusion (Links et al. 2019).

Jordanian doctors may switch between their languages during the conversation with monolingual patients. CS (code-switching) is commonly used by bilingual speakers, who switch from one language to another (Buda 2006, as cited in Dalamu 2019; Taweel \& Btoosh 2012). According to Müller et al. (2014: 50), CS simply refers to the process of "moving from one meaning-making, or symbolic system (a code) to another". CS is caused by several factors, including the individual's linguistic knowledge or competence, as reflected in his or her performance. With respect to the educational background of doctors, they code-switch when using medical terms and some English words (Sallo 1994) in order to ensure effective healthcare communication.

In health communication, communication accommodation theory (CAT) explains CS between doctors and patients which is determined by their psycholinguistic and social motivations during conversation (Giles 1975, 2016; Giles \& Smith 1979; Giles et al. 1991; Gallois et al. 2005; Giles \& Ogay 2007). Within health communication, there are two approaches to understanding why communicators switch from one language to another: a psycholinguistic approach and a social approach. 
A psycholinguistic approach is concerned with the bilingual processing of language in natural discourse in terms of language production, comprehension, and acquisition (Kootstra 2015). Psycholinguists attempt to gain a better understanding of how languages are stored in the brain and the encoding language process that is selected. For example, Meuter (2005) suggests three main factors relevant to the selection of a language: relative proficiency, contextual cues, and monitoring ability. The subconscious nature of language selection would not preclude speakers from CS, as speakers are not always aware of the reasons for doing so. This paper posits that the primary psycholinguistic motivation for CS in the bilingual act of selecting a particular language is because of the accessibility or inaccessibility of the language due to difficulties in lexical access and gaps between the languages in the dialogue.

From a social point of view, pertinent factors contribute to the use of CS in a particular situation. Gardner-Chloros (2009) argues that three factors can affect speakers' linguistic behavior on whether to code-switch in their conversations. These include a) economic "market", prestige and power relations, b) the speakers' linguistic competence, their social status, their language ideologies and language attitudes, their self-perception and perception of others, and c) conversations where CS occurs as a tool to structure discourse of bilinguals. In this study, CS is understood as being used by bilinguals to accommodate the language choice of the interlocutor either to diverge (Ahmed \& Bates 2016; Links et al. 2019) or equalize power relations between them (Scotton 1988; Gardner-Chloros 2009; Fawole 2014).

CS is thereby a natural outcome of languages in interaction (Magana 2013) and is commonly observed in interactions where a minimum of two languages (or dialects or registers) within a specific genre (song, talk) are used interchangeably during a discourse occasion and regularly in multilingual settings (Eastman 1992). CS has been studied extensively in the education workplace, for educational purposes (Moodley 2007; Al Masaeed 2013; Mahsain 2015) and in dialects studies (Almhairat 2015; Al Hayek 2016). Few studies have examined the CS process in the healthcare environment (Alhamami 2020). Singo (2014) states that CS is a strategic tool for effective communication in doctor-patient (D-P) interactions, particularly when the conversation is in the second language. It can convey the message, converge with the client, maintain interpersonal relationships, and helps ease the potential embarrassment from taboo words or topics. However, it is not the intention of this study to investigate whether CS was employed by speakers consciously or unconsciously. Its purpose is rather to better understand doctors' use of CS and motivations of CS in health communication within the medical environment in Jordan.

Given the need to understand the reasons why CS is used in D-P interactions, the purpose of this study is to identify the extent to which the language 
of instruction in medical science has an impact on doctors' communication with patients for CS between English and Arabic languages during medical consultations in Jordan. Second, it attempts to identify the psycholinguistic and social motivations for CS between English and Arabic languages during medical consultations. The doctors, as bilingual speakers based on their educational background (Al-Hamwan 2015), maintained the use of English terminology rather than changing to Standardized Arabic Language, perhaps due to their habitual use of the terms and training received in English. In these situations, filling the lexical gap via CS is considered a strategy to improve communication.

\section{Methodology}

This study was conducted in a public hospital in Jordan. A qualitative method was used to investigate CS instances among doctors and patients during medical consultation. This enabled the researchers to observe the fine-grained details of everyday events and the phenomena under investigation (Schillinger et al. 2002; Flick 2014), and to observe and gather data in the natural setting (Yin 2015). Data for this project were collected using semi-structured interviews that were recorded. Semi-structured interviews were used as they give participants the freedom to express thoughts and feelings in the privacy of a one-on-one encounter (Croucher \& Cronn-Mills 2014). In addition to the interviews, the researchers observed and noted the interactions between the doctors and patients during the medical treatments (Taiwo 2013).

\subsection{Participants}

Given the bilingual educational background, most doctors speak Arabic (the local dialect), English and languages other than English. Moreover, they use different local dialects, the Northern dialect and Southern dialect. To recruit doctors who work and are specialised in general internal medicine at the public hospital in Jordan from both genders, an email was sent to the clinic receptionist, who in turn sent the email to potential participants to invite them to take part in the research. Nine doctors (eight males \& one female) (see appendix A) participated in the study; all were bilingual (Arabic, English, and languages other than English) due to their medical education.

Patients aged 18 years and over were invited to participate in the research by the doctors who were on board and who agreed to participate in this project. Returning patients for minor or routine follow-up on non-sensitive illnesses or injuries were invited to participate in the research through leaflets which were handed to them by the receptionist. The leaflet information included contact details of the researcher for further information about the research. With regard to the time of participation, the patients were given sufficient time to make their decision. The patients received the Participant Information Sheet and those who agreed to participate, completed 
and signed the Participant Consent Form. All the patients were observed, videotaped and interviewed in real medical settings. The research participants included 18 patients ( $\mathrm{n}=18$; 12 males \& 6 females) (see appendix B). Thirteen of them were monolingual in Arabic and five were bilingual in Arabic and English based on their education in English. The participants were selected according to three demographic categories (age, education, and gender) and to represent different cultural backgrounds and regions (urban or rural) in Jordan. Additionally, they completed a semi-structured interview in Arabic that required no more than 30 minutes of their time, and they were audio recorded only.

\subsection{Data collection}

Ethical approval for this research was gained from the Western Sydney University (WSU) Human Research Ethics Committee and informed consent was obtained from the public hospital as required prior to data collection. All the participants received an Information Sheet and signed a Consent Form acknowledging their consent to take part in the research. The Information Sheet contained relevant information about the project, the researchers' contact details, avenues of support if a participant felt distressed at any time and an assurance of anonymity and the ability to withdraw at any time without having to give reasons for the withdrawal (Holloway \& Wheeler 2013). The nature of the research questions required the recruitment of doctors and patients in real medical settings. Participants were informed that their participation was voluntary. They were reassured that the information they supplied would be kept confidential. Additionally, their names were omitted from the responses and pseudonyms were used to keep their identities confidential. Data were stored and managed in the WSU data management system.

D-P interactions were observed and videotaped in real medical settings. Additionally, they completed a semi-structured interview in Arabic that required no more than 30 minutes of their time. The interviews were audio-recorded only. The researchers used a video recorder for capturing verbal and nonverbal interaction between doctors and patients to develop an understanding of the CS involved and analyze the motives of such a phenomenon in the observed doctor-patient interaction. Nine GP doctors and 18 patients were asked open-ended questions in the interview; this provided a wide variety of responses and detailed descriptions of their experiences. By responding to open-ended questions in the interview in their own words, the respondents were able to convey their own experiences. Furthermore, this method allowed the patients to disclose vital and often "hidden facets of human and organizational behavior" (Qu \& Dumay 2011: 246) to yield rich data. Approximately 6 hours of audio-taped interviews were gathered for analysis. 


\subsection{Data analysis}

We employed thematic analysis (Owen 1984; Braun \& Clarke 2006; Guest et al. 2012) in an effort to understand how Arabic-English CS works in relation to power and control during medical consultations. The videos ranged between 01:18 and 17:76 minutes. The average length of the videos was 5.83. The video data yields 104.86 minutes total of 18 consultations, that is about 1.748 hours of language data. The interviews ranged between 05:40 and 30:05 minutes duration. The interviews data yielded 379.59 minutes total of 6.32 audio recordings. All the interviews were transcribed and translated into English.

The data collected from interviews were prepared for analysis using NVIVO 12 software. The researchers read all the interview transcripts several times to become familiar with the data and to initiate coding and detect themes. NVIVO facilitates connecting data and categories in three ways: visual coding, attributes, and node coding (Richards 1999) while offering substantial flexibility (Basit 2003; Mertens \& Wilson 2012). This was done as a part of the first author's PhD study in linguistics and this article is focused on CS. It was helpful to generate several nodes using NVIVO 12. In particular, the researchers used the framework by Braun \& Clarke (2006). This approach is inductive and encompasses a process that includes six phases of analysis: immersing with the data, generating initial codes, searching for themes, reviewing themes, and defining and naming themes. Thematic analysis yielded CS as a main CS as a main theme with two sub-themes in Table (3) as follows:

Table 3. Final theme from coding

\begin{tabular}{|l|l|}
\hline Themes & Sub-themes \\
\hline Codeswitching Motivations & $\begin{array}{l}\text { Filling a lexical gap } \\
\text { Accommodating the other party }\end{array}$ \\
\hline
\end{tabular}

\section{Motivations behind codeswitching}

CS is a strategy used by bilinguals to signal several psycholinguistic and social functions. As the medical encounter was observed, numerous CS instances among doctors and patients were noted during the medical consultation. The study found that Jordanian doctors usually code-switch for psycholinguistic and social reasons. Although all of the patients preferred conversing in Arabic, there were some instances of CS by bilingual doctors, who inserted English into Jordanian Arabic speech with participants who were addressed and supported. In this study, CS occurred for two main reasons: to fill lexical gaps and to facilitate communication. 


\subsection{Filling lexical gaps}

As bilingual participants who regularly alternate between English and Arabic (different dialects), the doctors used CS across the four phases of the medical encounter - obtaining medical history, clarifying information, revealing the diagnoses, and managing the condition (Heath 1992). This can be seen in Fragment 1. Mr Sami visited the hospital as he had difficulty breathing due to common cold symptoms, including cough, fever and a runny nose. Mr Sami described his health problem to Dr Salem who negotiated the information, that led to a diagnosis of flu.

Fragment 1 [Mr. Sami was a 37-year-old male patient with a high level of education, consulting with Dr Salem, a male GP doctor of 27 years old, educated in English.]

1 Dr Salem: متى بلثت هذي الأعر اض معك ؟

$2 \quad$ 'When did these symptoms start?'

3 Mr Sami: تقريبا صارلي يومين

$4 \quad$ 'Nearly, two days ago.'

5 Dr Salem: ' 'severity' من يومين على نفس '

$6 \quad$ 'Two days ago, with the same severity?'

7 Mr Sami: : نعم، نفس الثيء

8 'Yes, the same.'

9 Dr Salem: يعني (لل) نفس شدة المرض؟

10 'I mean, the um same severity of illness?'

11 Mr Sami: نعم، نفس الثيء

12 'Yes, the same.'

While the doctor generally avoided using medical English jargons in patient consultation, in some cases, he code-switched from Arabic to English, although this may not be obvious to the patient, such as using the English medical term 'severity' (Line 5). Here, the doctor was surprised that Mr Sami did not have his severe illness checked until two days later. Nor could he believe that his patient had not realized his severe medical condition so much so that he could not help uttering 'severity' in English. The doctor's paralinguistic cue such as 'um' (Line 9) was useful to refreshing the memory bank in case of switching to the Arabic language. Hence, CS was inserted because of the easier accessibility and retrieval from memory. As Mr Sami was well-educated, he did not seem to have difficulty understanding what the English word 'severity' meant, given the fact he replied and confirmed his reply without hesitation (see L7 and L11).

In his interaction with Mr. Sami, Dr Salem code-switched from English to Arabic and used the term 'شدة المرض' 'severity' not only to gather information about the patient's illness but also to accommodate his speech style with him. Another motivation for 
CS is for the sake of confirmation. Here, Dr Salem reiterated his question (Line 9) 'I mean, the same severity of illness?' to stress his message. The observation shows that Dr Salem repeated in Arabic what had already been said in English, in exact form, for emphasis and confirmed that his patient understood what had been said. This type of switch is identified by Gumperz (1982a) as repetition, which "may serve to clarify what is said, but often they simply amplify or emphasize a message" Gumperz (1982: 78) in Fragment 1. The doctor was proficient in English and used technical terms. However, the patient was brought up in Jordan with one language and was not as fluent in the medical register in English as the doctor. Nevertheless, the patient's reply showed that he had a high level of education in English as he confirmed twice 'Yes, the same'? (Line 8 \& 12).

Similarly, Dr Ali code-switched when interacting with Mr. Tamer in Fragment 2. In this instance, the doctor was clarifying information about the patient's illness and using the English terminology 'pain' due to the ease of retrieval of this from memory.

Fragment 2 [Mr Tamer, a male patient of 34 years old, his education level is secondary, was consulting with Dr Ali, a male GP doctor of 28 years old, educated in Ukraine.]

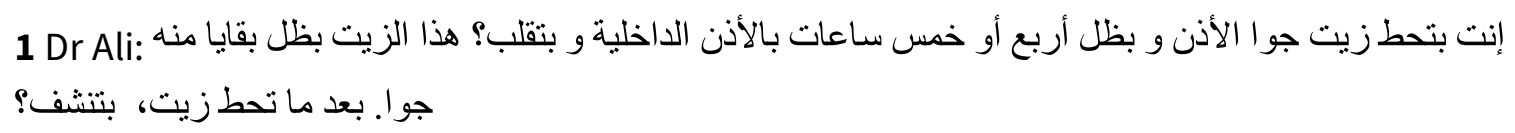

2 [You put oil into your ear, and it remains up to five hours and then you turn your head to the other side? Unfortunately, this oil can leave residues inside. Do you dry your ear after?]

3 Mr Tamer: آه بنشف

4 'Yes, I do.'

5 Dr Ali: بتشو بتشف؟

$6 \quad$ 'What do you use for that?'

7 Mr Tamer: بنشف بنفس منظف الأذان

8 'I usually dry with cotton swabs'

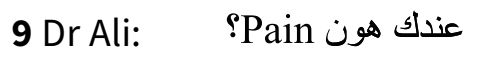

10 'Do you have a pain here?'

11 Mr Tamer: لاكيف؟

12 'No, I do not have'. 'What do you mean?'

13 Dr Ali: يعني وجع

14 'Pain means ache.'

15 Mr Tamer: نعم، في

16 'Yes, I have.'

To function effectively for better mutual understanding and to avoid misunderstanding, Dr Ali used the strategy of repair. Tarone (1980: 427) defined 'repair' as "the 
discoursal rules for who corrects whom, when and the correction of a linguistic form as well as negotiation of intended meaning”. Dr Salem deployed an immediate repair strategy after CS to ensure understanding of what had been uttered.

Dr Ali code switched due to the lack of immediate availability of the required word or for its ease of retrieval from memory (Gardner-Chloros 2009). Hence, he code-switched from Arabic to English within talk to fill a lexical gap. English synonyms were integrated either because of habitual use of the words or for their easier accessibility or retrieval from memory. According to Milroy and Muysken (1995), a speaker's choice of preference code depends largely on their life histories, which includes their social and educational factors. Thus, language codes may be switched at any point in the discourse due to the bilingualism of the doctors and their language preference.

This demonstrates that CS was used, where doctors filled in missing words or phrases from memory due to the psycholinguistic state of the speakers (Gardner-Chloros 2009; Jevtović et al. 2020). An insertion of words or phrases by speakers may also correlate with the fact that the words or phrases are retrieved more rapidly in dialogue (Ariffin \& Rafik-Galea 2009; Green \& Li 2014). This is in line with the findings of Mahsain (2015) and Al-Hourani \& Qasim (2016) in their studies conducted in the context of education.

\subsection{Accommodating through negotiation}

Despite the fact that the doctor and patient have social differences in relation to the power inequality (Giles \& Ogay 2007) and interaction, the doctor made attempts to alleviate these for effective communication purposes. To achieve this, the doctor used CS when monolingual patients did not understand his message. Hofstede and Bond (1988) describe this as power distance, that is the extent to which a culture believes and accepts unequal power in institutions and organizations. There is an implicit desire among doctors for patients to respect them for their medical expertise and specialized knowledge and skills (Cordella 2004). For example, in high power distance cultures, doctors may view themselves as having expert knowledge of patients' health barriers, instead of valuing themselves as being equal and cooperative (Lawton et al. 2015). Patients in medical consultations are often powerless and are reliant upon doctors as the experts on their complaints, thereby increasing the doctors' power in terms of their status and interpersonal roles in the clinical setting (Rocque \& Leanza 2015).

CS can also be seen as a tool to indicate accommodation between speakers. Gallois et al. (2005) state that speakers vary in their speech styles either to distance or strengthen the relationship between themselves and other speakers according to their social identity. For the purpose of convergence, they adapt their speech style with others. During the conversation, participants collaborate to create a meaningful message and achieve effective communication. This study showed that participants code-switched either to converge or equalize power relations between them. 
In Fragment 2, when the doctor used the English term "pain" to fill a lexical gap, the patient did not understand him and asked for clarification. The doctor code-switched from English into Arabic 'وجع' [pain] to accommodate the language needs of the patient. By virtue of the doctor's knowledge of his patient, he was able to accommodate to his patient's level of English proficiency (Wood 2019). The patient's failure to understand the doctor's English terminology, if not clarified, may have contributed to unsuccessful communication, potentially leading to failure in the treatment process.

While doctors commonly demonstrate their patronage over their patients through using CS to meet their language needs and ensure they understand medical advice, some patients would switch to English medical jargons to seek accommodation with the doctor, as in the example below:

Fragment 3 [Mr Fadi, a male patient, 46 years old, with high level of education and an undergraduate degree in dentistry, was consulting Dr Amjad, a male GP, 54 years old, educated in English.]

\section{Dr Amjad: شو مالك؟}

\section{$2 \quad$ 'What is your complaint?'}

3 Mr Fadi: انجرحت 'Trauma انعرضت ل'

4 'I have a trauma.'

5 Dr. Amjad: انجرحت ، اها؟

$6 \quad$ 'You were injured?'

7 Mr Fadi: من الليجو تبع الأطفال

8 'From lego for children.'

9 Dr Amjad: دعست عليها?

$10 \quad$ 'You fell off it?'

11 Mr Fadi: دعست عليها وما شفتها.

12 'I fell off it and I did not see it'

13 Dr Amjad: إلها حفة حادة؟

14 'Doe it have a sharp edge?'

15 Mr Fadi: نعم، صحيح

16

'Yes, right.'

In Fragment 3, the patient, Mr Fadi, is a dentist who had experienced trauma in his foot, and during the consultation switched to the English medical jargon term "trauma" (Line 3), seemingly to accommodate to the doctor. Mr Fadi attempted to identify himself with Dr Amjad as a fellow health professional. Mr Fadi is a dentist by profession and his use of the medical term may imply that he is not a layperson without knowledge of the medical field. Bullock and Toribio (2009) proposed that CS by proficient bilinguals may 
occur within particular cultural groups. Giles and Smith (1979) argued that individuals attempt to make themselves alike and intelligible to others by lessening their typical accents, slowing down their speech, and delivering their message with the listener's familiarity with the topic of discussion in mind. According to the CAT, the patient was accommodating the doctor by adjusting his speech behavior to that of the doctor. This indicates that this patient was trying to converge and suggest affiliation with the medical membership and recommend himself as an in-group member of clinical professional. However, the doctor's language choice distanced him from the patient (in this case, Arabic). According to CAT, if the speaker refuses to accommodate to the language of conversation of other interlocutors, this leads to divergence (Giles \& Smith 1979). D-P clinical interaction is more than just one-way information flow, such as the doctor giving medical advice and the patient simply following it. In fact, some patients may be engaged in social negotiation with the doctor. Fragment 4 is an example in case.

In Fragment 4, Dr Amjad advises the patient about the treatment for his trauma, but the patient Mr Fadi did not agree and strongly requested an alternate treatment, as observed in Fragment 4.

Fragment 4 [Dr Amjadcontinued his diagnosis and provided medical advice to Mr Fadi.]

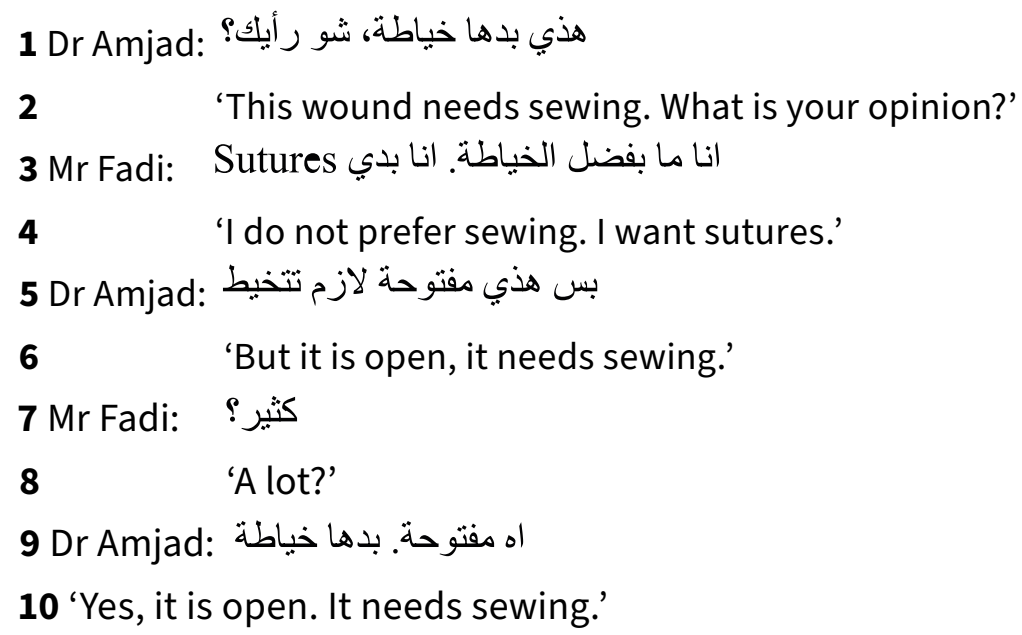

In Fragment 4, the patient's desire to converge brings familiarity and helps to create an informal environment. This can be explained using Giles's accommodation theory, that assumes that communicators adjust to a situation either to converge or to diverge from the listener. Mr Fadi code-switched from Arabic into English by using the term "sutures" (Line 3), that indicates the two important motives for convergence for him in Fragment 4; one is the desire to get approval for the suggested treatment from $\mathrm{Dr}$ Amjad. The evidence is that of similarity-attraction: The more similar we are to our interlocutor, the more he or she will like or respect us, and the more social approval 
we can expect to gain (Byme 1971, as cited in Giles \& Ogay 2007). Second, it is possible to break the power discrepancy created by the doctor's specialist status and bring the doctor and the patient closer (Youssef 1993). This can also be interpreted in terms of diglossia that the official language could be more attractive and more rational than the local language, Ferguson, cited in Fasold (1984), defined diglossia as:

A relatively stable language situation in which, in addition to the primary dialects of the language (which may include a standard or regional standards), there is a very divergent, highly codified (often grammatically more complex) superposed variety, the vehicle of a large and respected body of written literature, either of an earlier period or in another speech community, which is learned largely by formal education and is used for most written and formal spoken purposes but is not used by any sector of the community for ordinary conversation (Ferguson 1959: 336).

Consequently, using English terms by this patient could be considered as prestigious and as a way of expressing convergence with the doctor (Singo 2014).

On the other hand, Dr Amjad again did not adapt to Mr Fadi's speech and this asserted his medical expertise and influential role as a medical professional while emphasizing Mr Fadi's role as a patient under treatment. Emphasizing the differences in speech leads to divergence between speakers. This is similar to Gumperz's (1982b) notion of 'we-code' and 'they-code,' in which interlocutors differ in communication behavior according to their relationship with the other interlocutors during the language interactions and its motivational factor for CS. For this reason, the CAT aims to identify the motivational factors behind the variation in speech styles.

When two speakers converse, convergence between them can also take place in relation to the content of what they say. Speakers can defer to the listener and increase mutual clarification as they believe that the listener holds the knowledge (Giles \& Smith 1979). For example, that was mentioned before (see Fragment 3.1) in the consultation with the patient, Mr Sami (male, 37), the patient replied to the question, 'severity' with an expected adjacency 'yes, the same'. This type of CS is motivated by the content of the preceding question.

This key finding is similar to what other studies (Singo 2014; Wood 2019) show, i.e. that CS is a strategy used by speakers seeking to diverge and converge in their speech to accommodate the other interlocutors for effective communication. The use of CS in the accommodation situation not only enhances communication, but it also provides "the bridging of language separation" (Mabule 2015: 345).

CS can also improve a patient's comprehension. If the doctors speak the patients' language, dialect, vocabulary, or other types of speech varieties, the patients can 
understand them, and that leads to a potential increase in patient adherence, confidence and overall satisfaction with the medical consultation.

\section{Conclusion}

In this article, we find that CS played the roles of filling a lexical gap and accommodating to other speaker's talk in Jordanian doctor-patient interaction. The analysis shows that CS can be identified as filling a lexical gap when participants switch from Arabic to English within talk due to the unavailability of a word or phrase in their mother tongue, Jordanian Arabic, or for their easier accessibility or retrieval from memory. A unique function of CS was observed as the desire to bring familiarity and create an informal environment during the interaction between doctors and their patients.

The study has important implications for Jordanian medical healthcare services providers for professional training purposes. We have identified two useful communication strategies used by Jordanian doctors and patients for effective and successful communication. The results could be used to inform the professional development needs of the doctors in Jordan and medical professionals in other parts of the world.

\section{Acknowledgements}

We sincerely thank all participants in this study including doctors, patients and the receptionist who provided us with an unsparing cooperation. The budget for conducting this study has been provided by Western Sydney University.

Appendix A. Table 1. Basic Demographics of the Doctors

\begin{tabular}{|c|l|c|c|c|}
\hline No. & Pseudonym & Gender & $\begin{array}{c}\text { Education/medical } \\
\text { education }(\mathbf{B M}, \\
\text { ME, or higher })\end{array}$ & $\begin{array}{c}\text { Work experience } \\
(\mathbf{1} \text { year-over 10 })\end{array}$ \\
\hline 1 & Dr Amjad & male & English / BM & Expert \\
\hline 2 & Dr Shadi & male & English / BM & Expert \\
\hline 3 & Dr Adel & male & Not English / BM & Experienced \\
\hline 4 & Dr Ali & male & Not English / BM & Inexperienced \\
\hline 5 & Dr Hassan & male & English / BM & Inexperienced \\
\hline 6 & Dr Nabeel & male & Not English / BM & Inexperienced \\
\hline 7 & Dr Sabri & male & English / BM & Inexperienced \\
\hline 8 & Dr Salem & male & English / BM & Inexperienced \\
\hline 9 & Dr Asma & female & English / BM & Inexperienced \\
\hline
\end{tabular}


Appendix B. Table 2. Basic Demographics of the Patients

\begin{tabular}{|c|c|c|c|c|c|}
\hline No. & Pseudonym & Age & Gender & Education & Bilingual (Arabic-English) \\
\hline 1 & Fadi & 46 & male & $\begin{array}{c}\text { Higher } \\
\text { education }\end{array}$ & Bilingual \\
\hline 2 & Jasser & 24 & male & $\begin{array}{c}\text { Higher } \\
\text { education }\end{array}$ & Bilingual \\
\hline 3 & Murad & 46 & male & $\begin{array}{l}\text { Higher } \\
\text { education }\end{array}$ & Bilingual \\
\hline 4 & Muneer & 41 & male & $\begin{array}{c}\text { Higher } \\
\text { education }\end{array}$ & Bilingual \\
\hline 5 & Sameh & 37 & male & $\begin{array}{c}\text { Higher } \\
\text { education }\end{array}$ & Bilingual \\
\hline 6 & Ameer & 32 & male & Diploma & Monolingual \\
\hline 7 & Ahmed & 24 & male & Secondary & Monolingual \\
\hline 8 & Qais & 32 & male & Secondary & Monolingual \\
\hline 9 & Sameeh & 51 & male & Secondary & Monolingual \\
\hline 10 & Tamer & 34 & male & Secondary & Monolingual \\
\hline 11 & Ma'moun & 65 & male & Elementary & Monolingual \\
\hline 12 & Sami & 78 & male & Elementary & Monolingual \\
\hline 13 & Areen & 40 & female & Diploma & Monolingual \\
\hline 14 & Ayat & 35 & female & Secondary & Monolingual \\
\hline 15 & Rana & 27 & female & Secondary & Monolingual \\
\hline 16 & Haleema & 40 & female & Elementary & Monolingual \\
\hline 17 & Muna & 42 & female & Elementary & Monolingual \\
\hline 18 & Shayma'a & 55 & female & Not educated & Monolingual \\
\hline
\end{tabular}

\section{References}

Ahmed, R. \& Bates, B. R. 2016. To accommodate, or not to accommodate: Exploring patient satisfaction with doctors' accommodative behavior during the clinical encounter. Journal of Communication in Healthcare 9: 22-32.

Al-Hamwan, M. S. 2015. Arabic-English Codeswitching among Doctors and Nurses in Jordanian Hospitals Work Setting: Motivations and Attitudes [Unpublished Master's thesis]. Yarmouk University, Irbid, Jordan.

Al-Hourani, M. \& Qasim, A. 2016. The Use Code Switching Between Arabic and English Languages Among Bilingual Jordanian Speakers in Malaysia [Unpublished PhD dissertation]. Universiti Sains Islam Malaysia.

Al-Wer, E. 2005. Variation in Arabic languages. In: K. Brown (ed.), The Encyclopedia of Language and Linguistics. Oxford: Elsevier. 
Al Hayek, R. S. 2016. Arabic-English Code-Mixing by Jordanian University Students [Unpublished $\mathrm{PhD}$ dissertation]. Western Sydney University.

Al Masaeed, K. 2013. Functions of Arabic-English code-switching: Sociolinguistic insights from a study abroad program [Unpublished PhD dissertation]. The University of Arizona.

Alhamami, M. 2020. Switching of language varieties in Saudi multilingual hospitals: insiders' experiences. Journal of Multilingual and Multicultural Development 41(2): 175-189. Almhairat, A. S. 2015. Code-switching from the Jordanian Bedouin Dialect to the Jordanian Urban Dialect, in Amman: A Sociolinguistic Study [Unpublished Master's thesis]. Middle East University, Jordan.

Ariffin, K. \& Rafik-Galea, S. 2009. Code-switching as a communication device in conversation. Language \& Society Newsletter 5 (http://www.crisaps.it/newsletter/Winter\%20 2009\%20Ariffin.pdf).

Basit, T. 2003. Manual or electronic? The role of coding in qualitative data analysis. Educational Research 45: 143-54.

Braun, V. \& Clarke, V. 2006. Using thematic analysis in psychology. Qualitative Research in Psychology 3(2): 77-101.

Bullock, B. E. \& Toribio, A. J. 2009. The Cambridge Handbook of Linguistic Code-switching. Cambridge: Cambridge University Press.

Cordella, M. 2004. Dynamic Consultation: A Discourse Analytical Study of Doctor-Patient Communication. Amsterdam/Philadelphia: John Benjamins.

Croucher, S. M. \& Cronn-Mills, D. 2014. Understanding Communication Research Methods: $A$ Theoretical and Practical Approach. New York: Taylor and Francis.

Dalamu, T.O. 2019. Language choice as discourse: A transitivity approach to MTN and ETISALAT advertising communicative webs in Nigeria. Crossroads. A Journal of English Studies 25: 4-27.

Eastman, C.M. 1992. Codeswitching as an urban language-contact phenomenon. Journal of Multilingual and Multicultural Development 13: 1-17.

Fage-Butler, A.M. \& Jensen, M.N. 2016. Medical terminology in online patient-patient communication: evidence of high health literacy? Health Expectations 19: 643-53.

Farahani, M. A., Sahragard, R., Carroll, J. K. \& Mohammadi, E. 2011. Communication barriers to patient education in cardiac inpatient care: A qualitative study of multiple perspectives. International Journal of Nursing Practice 17: 322-28.

Fasold, R. W. 1984. The Sociolinguistics of Society. Oxford: Blackwell.

Fawole, A. A. 2014. Communication Strategies Of English-Speaking Foreign Medical Doctors in the Limpopo Province [Unpublished PhD dissertation]. University of Limpopo.

Ferguson, C.A. 1959. Diglossia. WORD 15: 325-40.

Flick, U. 2014. An Introduction to Qualitative Research. Los Angeles: SAGE. 
Galanti, G.-A. 2014. Caring for Patients from Different Cultures. Philadelphia: University of Pennsylvania Press.

Gallois, C., Ogay, T. \& Giles, H. 2005. Communication Accommodation Theory: A look back and a look ahead. In: W.B. Gudykunst (ed.), 121-148. Theorizing about Intercultural Communication. Thousand Oaks: Sage.

Gardner-Chloros, P. 2009. Code-switching. Cambridge: Cambridge University Press.

Giles, H. 1975. Speech Style and Social Evaluation. New York: Academic Press.

Giles, H. 2016. The social origins of CAT. In: H. Giles (ed.), Communication Accommodation Theory: Negotiating Personal Relationships and Social Identities across Contexts, 1-10. Cambridge: Cambridge University Press.

Giles, H., Coupland, J. \& Coupland, N. 1991. Contexts of Accommodation: Developments in Applied Sociolinguistics. Cambridge: Cambridge University Press.

Giles, H. \& Ogay, T. 2007. Communication accommodation theory. In: B. B. Whaley \& W. Samter (eds.), Explaining Communication: Contemporary Theories and Exemplars. Mahwah, New Jersey: Lawrence Erlbaum Associates.

Giles, H. \& Smith, P. 1979. Accommodation theory: Optimal levels of convergence. In: H. Giles \& R.N. St. Clair (eds.), Language and Social Psychology. Oxford: Blackwell.

Green, D. W. \& Li, W. 2014. A control process model of code-switching. Language, Cognition and Neuroscience 29: 499-511.

Guest, G., MacQueen, K. M. \& Namey, E. E. 2012. Applied Thematic Analysis. Thousand Oaks: Sage.

Gumperz, J. J. 1982a. Discourse Strategies. Cambridge: Cambridge University Press.

Hamdan, J.M. \& Hatab, A.W.A. 2009. English in the Jordanian context. World Englishes 28: 394-405.

Hamers, J.F. \& Blanc, M.H.A. 2000. Bilinguality and Bilingualism. Cambridge: Cambridge University Press.

Heath, C. 1992. The delivery and reception of diagnosis in the general practice consultation. In: P. Drew \& J. Heritage (eds.), Talk at Work: Interaction in Institutional Settings, 235-267. Cambridge: Cambridge University Press.

Hofstede, G. \& Bond, M.H. 1988. The Confucius connection: From cultural roots to economic growth. Organizational Dynamics 16: 5-21.

Holloway, I. \& Wheeler, S. 2013. Qualitative Research in Nursing and Healthcare. Somerset: John Wiley \& Sons.

Jarbou, S.O. 2010. Accessibility vs. physical proximity: An analysis of exophoric demonstrative practice in Spoken Jordanian Arabic. Journal of Pragmatics 42: 3078-3097.

Jevtović, M., Duñabeitia, J.A. \& de Bruin, A. 2020. How do bilinguals switch between languages in different interactional contexts? A comparison between voluntary and mandatory language switching. Bilingualism: Language and Cognition 23: 401-13. 
Kootstra, G.J. 2015. A psycholinguistic perspective on code-switching: Lexical, structural, and socio-interactive processes. In: G. Stell \& K. Yakpo (eds.), Code-Switching between Structural and Sociolinguistic Perspectives, 39-64. Berlin/Boston: De Gruyter.

Lawton, B., Mahoney, M., Pelliccio, L. \& Pelliccio, L. 2015. A comparative study of the utility of new media technologies and power distance in doctor-patient communication in the Philippines and the United States. Journal of Intercultural Communication 38. Retrieved from http://digitalcommons.wcupa.edu/comstudies_facpub/6.

Links, A.R., Callon, W., Wasserman, C., Walsh, J., Beach, M.C. \& Boss, E.F. 2019. Surgeon use of medical jargon with parents in the outpatient setting. Patient Education and Counseling 102(6): 1111-1118.

Mabule, D.R. 2015. What is this? Is it code switching, code mixing or language alternating? Journal of Educational and Social Research 5: 339.

Magana, D.A. 2013. Language, Latinos, and Healthcare: Discourse Analysis of the Spanish Psychiatric Interview [Unpublished PhD dissertation]. University of California, Davis.

Mahsain, F. 2015. Motivations Behind Code-Switching Among Kuwaiti Bilingual Schools Students [Unpublished PhD dissertation]. University of Manchester.

Mertens, D.M. \& Wilson, A.T. 2012. Program Evaluation Theory and Practice: A Comprehensive Guide. New York: Guilford Publications.

Meuter, R.F.I. 2005. Language selection in bilinguals: Mechanisms and processes. In: J.F. Kroll \& de Groot, A.M.B. (eds.), Handbook of Bilingualism: Psycholinguistic Approaches, 349-370. New York: Oxford University Press.

Milroy, L. \& Muysken, P. 1995. One Speaker, Two Languages: Cross-disciplinary Perspectives on Code-switching. Cambridge: Cambridge University Press.

Moodley, V. 2007. Codeswitching in the multilingual English first language classroom. International Journal of Bilingual Education and Bilingualism 10: 707-22.

Müller, C., Cienki, A., Fricke, E., Ladewig, S., McNeill, D. \& Tessendorf, S. (eds.) 2014. Body - Language - Communication: An International Handbook on Multimodality in Human Interaction. Berlin: De Gruyter Mouton.

Nilep, C. 2006. "Code switching" in sociocultural linguistics. Colorado Research in Linguistics 19: 1-22.

O’Connell, R. L., Hartridge-Lambert, S. K. , Din, N., St John, E.R., Hitchins, C. \& Johnson, T. 2013. Patients' understanding of medical terminology used in the breast clinic. Breast 22: 836-838.

Obeidat, R. \& Khrais, H.I. 2016. Jordanian physicians' attitudes toward disclosure of cancer information and patient participation in treatment decision-making. Asia-Pacific Journal of Oncology Nursing 3: 281-288.

Owen, W.F. 1984. Interpretive themes in relational communication. Quarterly Journal of Speech 70: 274-287. 
Qu, S.Q. \& Dumay, J. 2011. The qualitative research interview. Qualitative Research in Accounting \& Management 8: 238-264.

Richards, L. 1999. Using NVivo in Qualitative Research. London: Sage.

Rocque, R. \& Leanza, Y. 2015. A systematic review of patients' experiences in communicating with primary care physicians: Intercultural encounters and a balance between vulnerability and integrity. PLoS One 10: 1.

Sallo, I.K. 1994. Arabic-English code-switching at the university: A sociolinguistic study. In: R. de Beaugrande, A. Shunnaq \& M.H. Heliel (eds.), Language, Discourse and Translation in the West and Middle East, 115-132. Amsterdam: John Benjamins.

Schillinger, D., Grumbach, K., Piette, J., Wang, F., Osmond, D., Daher, C., Palacios, J., Diaz Sullivan, G., Bindman, A.B. 2002. Association of health literacy with diabetes outcomes. JAMA 288: 475-482.

Scotton, C.M. 1988. Self-enhancing codeswitching as interactional power. Language E Communication 8: 199-211.

Simmons, M. 1998. A sociolinguistic analysis of doctor-patient communication. In: The Japan Conference on English for Specific Purposes Proceedings. Aizuwakamatsu City, Fukushima, Japan: ERIC Documents Reproduction Service.

Singo, J. 2014. Code-switching in doctor-patient communication. NAWA Journal of Language \& Communication 8(1): 48-56.

Suleiman, S.M. 1985. Jordanian Arabic between Diglossia and Bilingualism. Amsterdam: Benjamins.

Taiwo, C.C. 2013. Exploring health literacy among a selected Nigerian population: An ethnographic study [Unpublished PhD dissertation]. University of Phoenix.

Tarone, E. 1980. Communication strategies, foreigner talk, and repair in interlanguage. Language Learning 30(2): 417-428.

Taweel, A.Q. \& Btoosh, M.A. 2012. Syntactic aspects of Jordanian Arabic-English intrasentential code-switching. Linguistica Online 1-21.

Wood, N.I. 2019. Departing from doctor-speak: A perspective on code-switching in the medical setting. Journal of General Internal Medicine 34: 464-66.

Yin, R.K. 2015. Qualitative Research from Start to Finish. New York/London: Guilford Publications.

Youssef, V. 1993. Marking solidarity across the Trinidad speech community: The use of an ting in medical counselling to break down power differentials. Discourse E Society 4: 291-306.

$* * *$

Etaf Alkhlaifat is currently a $\mathrm{PhD}$ candidate at Western Sydney University. Her current research is "A Sociolinguistic Study of Doctor-Patient Interaction in Healthcare Settings: A Jordanian Perspective”. She has completed her bachelor's degree in German and English 
(double major) at the University of Jordan in 2002 and a Masters in English Language Teaching and Curriculum at Mutah University in Jordan in 2007. Etaf has worked as an English teacher in the Ministry of Education in Jordan from 2002 to 2008 and then she started her work as a lecturer in both universities King Faisal University and Dammam University in Saudi Arabia from 2008 to 2015. She has also worked as a casual lecturer and tutor at Western Sydney University, Sydney, Australia in 2017, 2018 and 2020.

Ping Yang is Senior Lecturer in Linguistics and an Academic Course Advisor for the Master of Arts (TESOL) course in the School of Humanities and Communication Arts at Western Sydney University. Dr Yang holds a PhD in Linguistics from Macquarie University, Australia. His teaching and research areas include intercultural communication, nonverbal communication, socio-cultural linguistics, TESOL teacher education, and English-Chinese translation studies. Dr Yang has supervised $\mathrm{PhD}$ candidates and has actively published books, book chapters, and peer-reviewed journal articles in these research areas. (https://www.westernsydney.edu.au/staff_profiles/uws_profiles/ doctor_ping_yang).

Mohamed Moustakim is a Senior Lecturer in Education in the School of Education, Western Sydney University, Australia. He completed a Doctorate in Education at Exeter University in the United Kingdom. Before joining WSU, Mohamed held academic posts in a number of Higher Education Institutions in the UK, including, the University of East London, the University of Greenwich, the College of St Mark \& St John and St Mary's University College. His teaching and research are focused on equity and diversity in Education and he is currently supervising several $\mathrm{PhD}$ students whose research focus is on sociolinguistics. (https://www.westernsydney.edu.au/staff_profiles/WSU/ doctor_mohamed_moustakim) 